\title{
Corpo, aparelho e auto-imagem
}

Gabriel de Barcelos

\section{Resumo:}

Este texto contém a parte inicial de minha pesquisa de mestrado, onde procuro investigar algumas formas de auto-imagem contemporânea, com a utilização das tecnologias mais recentes. Meu trabalho centra-se nos vídeos com características performáticas, disponibilizados na internet, em especial os feitos com o advento da webcam. Mas, nesta etapa introdutória, pretendi fazer um recorte na história dos aparelhos e mecanismos produtores de imagens que antecederam (e precederam) o que hoje conhecemos como cinema, pensando as transformações da subjetividade, do registro do corpo e da auto-representação do indivíduo.

\section{Palavras Chave:}

corpo, tecnologia, auto-imagem, subjetividade

\begin{abstract}
:
This article contains the inicial part of my Master's degree research, which I try to investigate some forms of self image contemporary using most advanced technologies. My research is focused on vídeos with performatic characteristics, available on the Internet, specially those produced with webcams. However, in this introductory part, I intend to focus on the devices and mechanisms producing images which foresee (and antecipate) what today is known as the cinema, thinking about subjectivity, body and self representation transformations.
\end{abstract}

\section{Keywords:}

body, technology, self-image, subjectivity

\section{Máquinas de (auto) imagem}

Da reportagem televisiva ao colóquio, da mesa de bar à sala de aula... Uma das grandes discussões presentes hoje é sobre as chamadas "novas tecnologias". Ao falar sobre o tema, diversos lugares-comuns podem nos vir à mente: "democratização da informação", "comunicação com o mundo", "diversidade dos meios", "grande acessibilidade", além de incontáveis outros. Ao pesquisar este assunto, podemos utilizar os recortes mais inusitados, além de diferentes linhas teóricas e propostas metodológicas.

Podemos constatar através de um simples olhar na grande mídia, nas conversas ou em discussões técnicas ou acadêmicas, um grande otimismo com o possível poder transformador destas mídias digitais. Outra característica comum é a glamourização do que seria uma novidade, algo totalmente diferente do que até então era conhecido. Philippe Dubois (2004: 35) fala sobre “(...) um efeito de profetismo: trata-se de sempre de enunciar uma visão sobre o futuro ('de agora em diante, nada será como antes, tudo vai mudar, está surgindo um mundo diferente que não podemos perder' etc.), que tem, em última análise, um potencial de tipo econômico". Para o autor, isto guarda uma dupla ideologia. De um lado, a da "ruptura", da "tábula rasa" e da "recusa da história". De outro, a do "progresso contínuo", a idealização de uma tecnologia linear e salvadora. 
Dentro deste universo, o cinema encontra-se em importante momento. As imagens em movimento estão em toda parte: no celular, no sistema de vigilância da loja, no computador, na TV, além, claro, das salas de exibição. Estes aparelhos engendram mudanças nas relações subjetivas, promovendo diferentes formas de relação do corpo com as imagens e do sujeito com o aparelho.

Poderíamos pensar, em um primeiro momento, no percurso simples que vai do nascimento da exibição nas salas de cinema até a sua progressiva saída, com a TV, o vídeo, o DVD e a internet. Apesar deste caminho não poder ser recusado totalmente, a complexidade da questão exige uma atenção mais completa ao pensarmos a influência dos meios técnicos.

No início do primeiro texto de seu livro «Cinema, vídeo, Godard» (Ibidem: 31), Dubois ressalta que "não foi preciso esperar o advento do computador para se engendrarem imagens sobre bases tecnológicas". Para ele, "toda imagem, mesmo a mais arcaica, requer uma tecnologia (de produção, ao menos e por vezes de recepção), pois pressupõe um gesto de fabricação de artefatos por meio de instrumentos, regras e condições de eficácia, assim como de um saber". O teórico, para exemplificar a afirmação, cita os registros das cavernas do Paleolítico, as obras do Egito Antigo e as esculturas clássicas da Grécia, além de outros.

Para Dubois (Ibidem: 33), todas estas técnicas constituem "máquinas de imagens". Elas possuem "um dispositivo que institui uma esfera 'tecnológica' necessária à constituição da imagem: uma arte do fazer que necessita ao mesmo tempo de instrumentos (regras, procedimentos materiais, construções, peças) e de um funcionamento (processo, dinâmica, ação, agenciamento, jogo)".

Um momento importante nesta história será o Renascimento. A produção artístico-científica e os inventos deste período marcarão um novo estágio na construção do sujeito e sua relação com a técnica, ou como diz Dubois (Ibidem: 37), na questão "humanismo-maquinismo". Alguns aparelhos de visão desenvolvidos desde o século XV possuem importante influência no desenvolvimento de estudos e experimentações nas artes. Podemos falar das diferentes portinholas de Albrecht Dürer, que através de vidros, fios, molduras quadriculadas e outros instrumentos, buscava reproduzir a perspectiva. Ele acreditava que estes aspectos formais de uma pintura não poderiam ser concebidos de forma livre, mas de maneira artificial, seguindo princípios matemáticos. (SILVA, 2008). No mesmo século XV, Brunelleschi concebeu semelhante invento, a «tavoletta», que sobrepunha o objeto real e o a pintura, também na busca do entendimento perspectivista e do ponto de fuga.

Destes aparelhos, talvez o mais conhecido seja a câmara escura. Utilizada por alguns artistas do período e descrita por Leonardo Da Vinci, permitia, através de um pequeno orifício no local escuro, a reprodução das imagens, de forma invertida, em uma tela do lado oposto.

O compromisso racional moderno com a busca pela verdade encontra nos aparelhos utilizados importantes instrumentos para a prática artística. Contudo, estas máquinas possuíam apenas a função de visualizar ou refletir o objeto, cabendo ao artista pintar a partir daquela imagem. Segundo Dubois (Ibidem: 37) "toda a dimensão de humanismo artístico virá se insinuar nesta brecha: a personalidade do desenhista, a pincelada do pintor (...) tudo repousa nesta dimensão manual que marca e assina, por assim dizer, a inscrição do Sujeito na imagem".

Mas, apesar desta importante intervenção pictórica sobre a imagem produzida, Dubois insiste na relevância destes inventos para a relação indivíduo-aparelho e para a própria história dos meios. Para ele "(...) as máquinas, enquanto instrumentos (technè), são intermediários que vão se inserir entre o homem e o mundo no sistema de representação simbólica que é o princípio mesmo da representação" (2004: 35).

A representação imagética encontra, neste momento, uma experiência em que o registro do real é capturado 
mecanicamente ainda não como produto final, como será mais tarde a fotografia, (inspirada nos princípios da câmera escura), mas como modelo para a obra. O objeto em si, uma fruta ou um homem, por exemplo, é substituído por seu "duplo", produzido na câmara. Estabelece-se uma relação que ainda é bem pessoal como resultado final, mas é maquínica como processo.

Em Da Vinci, a relação corpo-máquina é ainda mais próxima, chegando até a sistemas de pensamento que fundiam estes dois pólos. Ele foi um investigador incansável da natureza e dos movimentos e tinha um interesse especial sobre o corpo humano como mecanismo. Em suas pesquisas, quis entender cada detalhe, cada movimento. Ao recorrer a seus manuscritos, podemos ver que para refletir sobre a arte ele introduz considerações sobre o funcionamento do olhar. Para demonstrar seu mecanismo, utiliza, então, alguns experimentos. O princípio da câmera escura é usado para provar que "os objetos transmitem suas imagens ou projeções, intersectando dentro do olho, no humor cristalino" (Ibidem). Acompanhado de um desenho explicativo, ele afirma que

isto é demonstrado quando as imagens de objetos iluminados penetram uma câmera escura,através de uma buraco redondo bem pequeno. Essas imagens, então, serão recebidas sobre um papel branco bem colocado nessa sala escura relativamente perto do buraco e veremos todos os objetos sobre o papel em suas formas e cores apropriadas (Ibidem).

O corpo, para Da Vinci, não era diferente de qualquer outra máquina, sendo possível, através da experimentação, sua decodificação. Simular estas funções era um importante recurso para o desenvolvimento de diversos aparelhos. Ao demonstrar o funcionamento do organismo, ele entendia, decodificava e criava, atos que não poderiam ser pensando de forma separada.

O Antropocentrismo e o Humanismo do período levam a instâncias de auto-reflexão até então desconhecidas, que passam por uma investigação contínua do corpo, este que é o alvo de um processo de desmitificação em relação à concepção medieval. Na Idade Média, a partir de uma visão predominantemente cristão, a materialidade humana, mesmo sendo considerada inferior em relação à alma, era sagrada por ser produto da criação divina. Da Vinci, assim como outros, desafiaram a moral e as leis daquele período de transição e realizaram a dissecação de cadáveres, considerada "profanação". Porém, a anatomia tornou-se uma disciplina cada vez mais importante durante a Era Moderna e grande objeto de interesse na pintura e na escultura.

As estruturas de autoreflexão, assim como o princípio da autonomia e da individualização burguesa moderna permitiram, durante o Renascimento, um florescimento dos auto-retratos, autobiografias ou obras com características autobiográficas (HELLER, 1982: 19). A modernidade possibilitou para a autobiografia a grande diferença de personalidades, a super-valorização da existência humana, a profunda importância da consciência intelectual e o dinamismo das modificações que poderiam acontecer na vida.

Ao falar de auto-retrato neste processo de transição do período medieval para o Renascimento é importante citar Albrecht Dürer. O artista alemão criador das portinholas produziu uma significativa obra de desenhos e pinturas baseadas na sua imagem, além de diários e anotações autobiográficas. Seus trabalhos mostram diferentes fases de sua vida, mostrando, também, através deles, as transformações da sociedade em que viveu. Nas representações de si próprio que pinta estão as diferenças de maturidade com a idade ou os cataclismas no século XVI (Ibidem: 198). Segundo Silvio Medeiros (2007), ele "pode ser considerado como o primeiro pintor obcecado pela própria auto-imagem".

É interessante notar que tanto em sua produção, como nas reflexões teóricas que deixou, Dürer sempre se baseou em rígidos critérios metodológicos, buscando sempre entender a essência do real para alcançar a beleza na criação (Ibidem). Sua técnica utilizava uma profunda matematização para alcançar seus objetivos, que passavam por um entendimento das "leis" que ordenavam todas as formas da natureza. Os vários inventos 
que inseriam as imagens do mundo em um mecanismo racionalizador são parte importante destas propostas.

Na sua obra existe um encontro do padrão objetivo com uma proposta profundamente subjetiva. Ele reflete ao mesmo tempo sobre elementos religiosos, como sobre valores interiores. Mas, combina isto a elementos bem objetivos da sua geometrização. Segundo Medeiros (Ibidem), "Dürer promoveu a união perfeita do real com o imaginário, circunscrevendo o delírio do imaginário em regras geométricas". A geometrização está em função de um elemento profundamente subjetivo.

O trabalho de Dürer é bem representativo do Renascimento, neste sentido: a técnica imagética e a busca pela reprodução mimética mecânica ao lado da subjetividade e da interiorização. A busca da imagem humana, no sentido moderno (profana, individual, terrena, com padrões de construção bem racionais) passa, neste período por toda a racionalização do método. As muitas e complexas técnicas de construção da imagem não nascem somente naquele momento, são fruto de toda uma história de transformações do campo da técnica. Contudo, é neste momento que estas máquinas vão fazer parte de uma construção metodológica bem definida e clara. Esta investigação tem na busca objetiva do real e das leis que regem as coisas uma ideologia, mas do que uma simples intenção isolada.

\section{Corpo e modernidade}

A Era Moderna foi o momento da imagem do ser humano, da auto-reflexão e do corpo como objeto de investigação contínua. Como vimos, no Renascimento isto foi motivo de interesse para artistas e cientistas, sendo a relação técnica-imagem-sujeito uma importante questão. Porém, o desenvolvimento dos aparelhos de imagens, aliados às ressignificações do corpo e da subjetividade não foram objeto apenas das ciências e das artes eruditas.

Arlindo Machado (2007: 76-77) lembra as origens do cinema no "mundo paralelo" das manifestações populares com origem na Idade média e no Renascimento, mas que prosseguiram pela Era Moderna e Contemporânea. O ambiente das feiras, festas, quermesses, circos, carroças de mambembes, diversos locais de atrações e exotismos eram locais preferenciais para o ilusionismo, a prestidigitação, a exibição de aberrações, os teatros ópticos, os jogos de sombras e desenhos. Estes eventos conquistavam a atenção e revelavam os princípios de cinema: ilusão, movimento, luz, sobra, efeitos.

Junto a isto, estes locais promoviam a contínua exposição dos corpos, seja na forma de diferentes performances ou na exploração do bizarro e do maravilhoso. Tendo como referência os estudos de Mikhail Bakhtin, Machado cita estes locais totalmente extra-oficiais, com seus jogos e diversões que se baseavam nos prazeres e necessidades corporais, nos risos, nas expressões grosseiras e profanações, além da ausência de delimitações e maniqueísmos morais.

Mesmo à margem da cultura oficial, estes eventos populares permaneceram na tradição européia pelos séculos que se seguiram do período moderno. Mas, com o avanço do desenvolvimento capitalista e sua ideologia protestante moralista, a convivência com estas práticas pouco suportáveis para as classes médias que se formavam tornava-se cada vez mais impossível. A saída foi o confinamento destes grupos em "guetos", que formariam, mais tarde, as periferias das grandes cidades.

Podemos citar alguns exemplos destas múltiplas imagens destes lugares, como a lanterna mágica, descrita pela primeira vez no início dos anos 1600. Consistia na projeção, em uma tela branca, de imagens invertidas, com o auxílio de lentes e de uma fonte de luz. Outras apresentações comuns eram as das sombras chinesas: milenar técnica de teatro com a utilização de bonecos e sombras. Estas atrações eram somente parte de um 
grande conjunto que incluía diversas modalidades de diversões. O ilusionismo das imagens não chamava nem mais, nem menos atenção do que os comediantes, as lutas, as deformações e todas as outras coisas. As apresentações também não exigiam uma atenção fixa, realizando os freqüentadores várias outras ações como comer, beber e festejar (MACHADO, 2007: 76-77).

Foi neste contexto que nasceram as primeiras experiências do cinema institucionalmente conhecido. Segregados nos cordões industriais, os primeiros filmes eram exibidos nos intervalos dos espetáculos de variedades chamados «music-halls» na Inglaterra, «café-concerts» na França, ou «vaudevilles» nos Estados Unidos. Como as obras eram de muito pequena duração e não-narrativas (com exibição de gags, danças, curiosidades...), era impossível ainda ser em uma atração principal.

Estes lugares eram o centro da diversão da classe operária urbana que crescia. Mal vistos pelas elites, os lugares viviam habitados pelas diversões das mais diversas, que incluíam o álcool, a música e a prostituição.

Os anos 1900 e o início do século XX constituem um grande momento de transição e transformação neste processo. A Revolução Industrial, a modernização, as modificações urbanas, o crescimento das cidades, os levantes proletários e diversos outros fatores caracterizaram um cenário de grandes rupturas e mudanças no cotidiano.

Segundo Charney e Schwartz (2001: 20), "a cultura da modernidade tornou inevitável algo como o cinema, uma vez que suas características desenvolveram-se a partir dos traços que definiram a vida moderna em geral". Desta forma, "a cultura da modernidade foi cinematográfica antes do cinema" (Ibidem). Ao falar de modernidade e cinema, é difícil pensar numa relação causal mecânica. Como os dois autores ressaltam, o conjunto de transformações ocorridas engendrou o ambiente em que o cinema se constitui como agente mais do que conseqüência.

A cidade do século XIX (que tem como maior ícone Paris e seu redesenho arquitetônico) é o centro sobre qual se erigiu a modernidade E o cinema não pode ser pensado separadamente dele. Elementos essenciais para a constituição do que seria conhecido como cinema já estavam nas esquinas das metrópoles. Podemos falar da "circulação de corpos e mercadorias, a troca de olhares e o exercício do consumismo". (Ibidem: 22) Também do "surgimento de uma cultura urbana metropolitana que levou a novas formas de entretenimento e lazer" (Ibidem). Além, também, do "reconhecimento um público, multidão ou audiência de massa que subordinou a sua resposta individual à coletividade" (Ibidem).

Estes muitos fatores se articulam para construir um indivíduo que está cercado entre todos os deslocamentos que testemunha e ao mesmo tempo protagoniza. As imagens em movimento têm importante papel nestas transformações, que envolvem novas relações com o tempo, o espaço e o movimento. Como afirma Benjamin, "uma das funções sociais mais importantes do cinema é criar um equilíbrio entre homem e aparelho" (1993: 189).

Estas relações, obviamente, não começam na sessão do «Grand Cafe», em 1895. Além de todas as mudanças citadas, podemos afirmar que poucos momentos da história possibilitaram tão profundamente um conceito mais amplo de cinema como aqueles anos. A “confusão" de eventos que concorriam entre si, em um quadro múltiplo de atrações e possibilidades técnicas e estéticas vai das décadas anteriores ao cinematógrafo Lumière e se perpetua no início do século XX.

Mas é importante lembrar que as primeiras exibições de filmes como os conhecemos hoje não foram nas sessões coletivas dos Lumière e sim nos aparelhos individuais inventadas por Thomas Edison. Em 1894, um ano antes dos operários e estações de trem serem vistas pelo público na famosa primeira exibição, foi inventado o quinetoscópio nos EUA. Através de uma moeda colocada na máquina, a pessoa poderia assistir, 
através de um pequeno visor, um curto filme. A invenção foi um sucesso e se espalhou por parques de diversão e casas de máquinas de divertimentos, as chamadas «penny arcades» (locais semelhantes aos atuais fliperamas, ou lojas de caça-níquel, com diferentes jogos mecânicos e eletrônicos) (COSTA, 1995: 10).

Duas importantes características podem ser ressaltadas ao falar deste invento. Primeiramente, podemos falar da particularidade da experiência solitária de assistir ao filme, em contraste com as futuras sessões coletivas. Neste momento, ao adentrar num local de diversão e escolher seu "brinquedo", o espectador embarca numa mais uma das diferentes máquinas do local. Ao olhar para o buraquinho e assistir às imagens, ele repete o procedimento de diversas atrações de circos e feiras, além dos «peepshows» e de próprios dispositivos do processo cinematográfico e seus visores, tais como o fenaquisticópio e o zootrópio.

Machado (2007: 124-125) ressalta, nesta atividade privada, a posição voyeurista do usuário do aparelho, que "espia" o conteúdo das imagens. Segundo ele, os temas tratados pelo filme envolvem o "erotismo do olhar, o desejo embutido no ato de ver" (imaginando o que seria para a época algo erótico): a dança de uma bela mulher, garotas brincando com trajes de dormir, um beijo, o halterofilista exibindo seus músculos. O autor acredita que este voyerismo está na própria origem da arte cinematográfica e é elemento presente até hoje: "(...) quando estamos no filme, submetemos a imagem- a imagem do outro- a um olhar concentrado e bisbilhoteiro, como se espiássemos pelo buraco da fechadura, ocultos nas trevas da sala de exibição”. Esta característica se aprofunda nos filmes pornográficos da produtora «Biograph» e na temática do observador curioso que está presente nos filmes do início do século XX.

A segunda questão relacionada ao quinetoscópio é complementar à primeira: a importante presença do corpo como objeto, instrumento ou veículo de sensações. Charney e Schwartz (2001: 21) afirmam que “(...) a percepção da vida moderna tornou-se atividade instável e o corpo do indivíduo moderno, tanto um tema de experimentação, quanto de novos discursos". Dizem ainda que “(...) o corpo tornou-se um ponto cada vez mais importante da modernidade, fosse como espectador, veículo de atenção, ícone de circulação ou local de desejo insaciável”.

Os primeiros filmes de Edison, no extremo oposto da tela grande dos Lumière permitiam a visão no diminuto espaço do aparelho. Era o local privilegiado para planos fechados dos seus personagens, muitas vezes em performances solitárias. Muito do que era visto no aparelho eram números comuns nas exibições do período. Talvez um dos mais famosos seja «Serpentine Dance», onde a dançarina Anabbelle dançava com seu figurino esvoaçante. Os movimentos circulares formam ondas de pano, provocando interessantes efeitos visuais para aquela nascente técnica. Outro conhecido personagem a se exibir para a câmera é o fisiculturista Sandow, em «Sandow» (The Strong Man). Ele se retorce em posições que evidenciam a sua forma física.

Nestes dois casos o personagem está virado para a câmera, reconhece a lente e se mostra. Não há qualquer ilusão de realidade e a relação entre quem vê e quem se faz visto é bem mais íntima. O corpo é, então, o personagem principal. No caso de Annabbelle, ele produz uma sensação hipnotizante, com a ajuda de adereços e constrói uma nova significação. No caso de Sandow a corporificação se orgulha e se detalha.

Na modernidade, quando a atenção é uma necessidade maior em um universo de várias opções, a máquina e o corpo se encontram em papel fundamental. O que será que era maior motivo de interesse? Os aparelhos como novidades técnicas que expandem os limites dos sentidos ou a materialidade corporal que se diferencia das muitas da multidão? Difícil é separar o pólo humano do maquínico, ainda mais quando falamos deste período do cinema e da modernidade com suas diversas experiências físicas na convivência com a velocidade, a linha de montagem, a eletricidade e diversos outros elementos.

Tanto no aparelho de Edison, como no dos Lumière, o corpo entra em um novo processo do efeito de identificação (ou estranhamento), subjetivação (ou alienação). O efeito de "espelho", que já havia passado por 
um profundo processo com a invenção da fotografia, chega a um diferente estágio. Aquela pequena janela de Edison que observava a performance, ou os filmes dos Lumière que mostravam cenas do cotidiano possibilitaram a observação do personagem "vivo", "independente", que saltava da esfera da representação para algo bem próximo da "vida real".

Ao falar sobre os filmes de atualidades, Benjamin (1993: 183-184) afirma que neles os indivíduos comuns têm a possibilidade de aparecer na tela. Portanto, conclui que "(...) cada pessoa, hoje em dia, pode reivindicar o direito de ser filmada". Ao citar as obras soviéticas, lembra que nelas as pessoas se "auto-representam", na maioria das vezes em seu local de trabalho.

O autor faz uma analogia destas possibilidades com alguns modelos de jornalismo e os seus espaços abertos para colaboradores. Nestas publicações, a classe trabalhadora (e não somente os intelectuais) poderia produzir textos, quebrando a separação entre leitores e escritores, especialistas e não-especialistas. A possibilidade de ser registrado pela câmera como um fator seria "aplicável, sem restrições ao cinema" (Ibidem), local onde "se realizaram numa década deslocamentos que duraram séculos no mundo das letras" (Ibidem). Obviamente, a oportunidade de acesso ao imenso aparato técnico e à condição de autor era algo totalmente impensável para a década de 30, momento de escrita do texto. A comparação da "auto-imagem" de um operário com a posição de um redator de jornal pode parecer, hoje, absurda. Contudo, é importante lembrar que havia pouco mais de três décadas de cinematógrafo, aparelho que produziu uma condição de representação considerada profundamente revolucionária na época.

Já não era nem o artista plástico, que com sua técnica pictórica e todo o seu processo registrava o corpo, nem a pessoa que interpretava para o público. Era um registro indicial, "vivo" do "real" que era capturado pela máquina. O trabalhador, que não era ator profissional, aparecia como num "teatro da verdade". E neste sentido era considerado transformador por Benjamin.

O teórico alemão levanta uma questão importante na comparação da escrita com o aparecimento no filme: a da autoria do corpo. As questões relativas ao autor já foram exaustivamente discutidas na crítica cinematográfica. Mas, neste momento, Benjamin ressalta as possibilidades criativas da imagem de um sujeito que se auto-afirma.

Benjamin, contudo, faz uma contraposição entre a produção da URSS e a da Europa Ocidental. Na primeira estaria presente a auto-representação libertadora feita pelos operários, que desta forma estariam inseridos como sujeitos de sua própria história (todas as críticas às limitações desta concepção, como falei anteriormente, devem observar o contexto em que estava inserido o texto). Já na segunda situação, o modo de produção capitalista impediria a "concretização da aspiração legítima do homem moderno de ser ver-se reproduzido". Ou seja, diferente da identificação que seria criada pelo filme soviético, as produções ocidentais provocariam (em especial nas mulheres, como lembra Benjamin) a fixação por ídolos e figuras estranhas ao universo do povo. Isto "corromperia" o interesse natural das massas pelo cinema e a sua necessidade, como consciência de classe, de se ver representado.

O que podemos refletir a partir destes pensamentos (e nesta comparação cinema-escrita) do autor frankfurtiano? Obviamente, as muitas transformações técnicas e culturais produziram e ajudaram a consolidar o discurso sobre o sujeito criativo do cinema: aquele que pensa e realiza o filme. Não é meu objetivo contestar a importância do realizador neste sentido. Mas, gostaria de voltar aos primeiros filmes do quinetoscópio para refletirmos sobre algumas questões que considero relevantes.

A dançarina Annabelle, o fisiculturista Sandow, os índios na dança-ritual de «Sioux Ghost Dance», o casal que se beija em «The Kiss», os dois homens que apostam na briga de galo em «Cock Fight», as cambalhotas de um homem em «Street Arab», a apresentação de um mágico em «The Magician»... Estes filmes, de certa 
forma, traziam para frente da câmera trechos de apresentações e performances, ou mesmo elementos da vida cotidiana. Sua atuação era pré-fílmica e muitos deles já eram conhecidos e haviam se apresentado para o mesmo público que freqüentava os locais onde eram vistos os filmes.

A equipe do rústico estúdio «Black Maria», de Edison, conduzia, claro, os personagens para a melhor adequação à câmera. Contudo, neste momento ainda bem empírico do cinema, o interesse era muito mais conseguir as imagens do que organizar qualquer espécie de «mise-en-scène». Por isso, recorrer a números conhecidos das apresentações populares, ou mesmo elementos do dia-a-dia.

Não podemos esquecer, também, que os quinetoscópios faziam parte de todo um contexto de diversões, onde aquelas apresentações exibidas estavam inseridas. Pelo menos em um primeiro momento, existiu uma primazia das muitas criações e possibilidades do corpo. Contudo, agora com uma mediação da máquina e também de outro sujeito que de certa forma contracena com ele: o diretor, produtor, cinegrafista.

Neste trabalho, não tenho como objetivo ficar voltando à exaustiva discussão sobre quem é o autor. Mas gostaria de pensar sobre o caráter do corpo nestes primeiros filmes, que transcende uma mera imposição artística e se compõe como uma forte expressão do indivíduo filmado.

A relação que gostaria de fazer é com a auto-reflexividade no cinema. Com as transformações técnicas e estéticas, o cinema se aproximou deste caráter de auto-imagem em muitos momentos. Isso aconteceu tanto nas diversas perspectivas autobiográficas e na possibilidade de se filmar. Dentro das propostas experimentais de Edison, pensar estas possibilidades centrando-se na figura do realizador seria impossível. Mas será que não podemos pensar diferente este processo? Não poderíamos pensar, dentro desta cinematografia, naquele que está sendo filmado como um sujeito que refere a si mesmo, não oferece qualquer ilusão naturalista se impõem como "ator", como aquele que age ativamente e constrói aquele discurso que está sendo produzido? Futuramente, as muitas obras auto-reflexivas apresentariam muitos outros caminhos para isto (a vídeoperformance, a vídeo-arte, os documentários autobiográficos, além de outros). Mas, será que não poderíamos falar que antes de vir a autobiografia, viria a performance? O corpo que fala e se manifesta como sujeito?

\section{Quinetoscópios e webcams}

Eu comecei a pensar nestas questões através de outro extremo cronológico: nos vídeos da internet que estou trabalhando. Inicialmente minha proposta era estudar as modificações da autoria no hipertexto através deste objeto. Partindo da discussão do tema pela Teoria do Cinema e da Literatura, além de outras bases teóricas, eu buscava o processo criativo de um realizador, com os conflitos e deslocamentos sofridos contemporaneamente com as tecnologias da informação. Como utilizava filmes performáticos, solitários, feitos em grande parte com webcams, iniciei o estudo sobre a autoreflexividade e a autobiografia no audiovisual.

Ao iniciar a pesquisa do corpus (filmes no You Tube), entretanto, percebi algumas particularidades. Existia uma dificuldade de aplicar os critérios tradicionais de autor como o realizador, o que pensa o filme e que o centra sobre a sua auto-imagem. Primeiramente, nem sempre a pessoa que se mostra controla a câmera, ou mesmo aparenta possuir a idéia de captar aquelas imagens. Um caso ainda mais diferente é «Lonely Girl 15», série de vídeos que me motivou a iniciar esta pesquisa. A protagonista adolescente destes filmes publicava vídeo-diários contando sobre o seu dia-a-dia, ganhando uma enorme legião de fãs. Algum tempo depois do sucesso descobriu-se que tudo era uma "farsa" produzida com atores e equipe técnica.

Nestes filmes, temos um só plano bem fechado, que ainda fica menor pela pequena tela de visualização do 
site. Em três, quatro ou cinco minutos estamos sozinhos com o personagem, com sua voz e com o seu corpo. Esta performance, mas do que tudo, marcaria a construção do filme. Portanto, antes de analisar a autoria stricto sensu, dentro do processo criativo que estamos acostumados a imaginar o audiovisual, seria muito mais importante imaginar uma poética do corpo. Antes de imaginar qualquer traço de uma autobiografia consciente, onde o videasta quer falar de si, seria interessante pensar uma auto-referência do personagem que atua e constrói a si mesmo diante da câmera, independente de qualquer intenção. Sua corporalidade e seu discurso verbal falam mais do que um projeto. Ao se exibir, reclamar, dançar ou fazer qualquer coisa em frente a uma webcam, ele se projeta, se performa e atua como si mesmo em um momento em que a esta substância corporal assume o papel criador.

E por que esta relação com as origens do cinema? Ao iniciar a pesquisa bibliográfica, juntamente, também, a debates sobre o meu projeto com outros pesquisadores, percebi que havia uma semelhança grande entre os períodos do chamado "primeiro cinema" e o momento atual. A grande diversidade de aparelhos, a indefinição e expansão do conceito de audiovisual, embora em contextos e particularidades radicalmente diferentes, poderiam ser pensados comparativamente. Além também da semelhança do caráter performativo, voyerista e exibicionista dos filmes feitos com webcams e os primeiros de Edison.

E qual é o sentido desta relação? Como expus no início deste capítulo, a história do cinema não pode ser pensada apenas a partir de 1895. Tendo como maior referência os estudos de Arlindo Machado, tentei entender toda a multiplicidade de meios e experimentações deste percurso de luzes, sombras, imagens e movimentos. Machado (2007: 14) afirma que "qualquer marco cronológico que (os historiadores) possam eleger como inaugural será sempre arbitrário, pois o desejo e a procura do cinema são tão velhos quanto a civilização de que somos filhos."

Então, por que não entender o cinema em toda esta diversidade de jogos, interações e contemplações das imagens, que abarcam desde o drive-in até o filme de celular? Do quinetoscópio ao 3D? Afinal, como diz o autor (Ibidem: 216):

“(...) fica cada vez mais difícil falar em cinema strictu sensu, ou mesmo sem vídeo strictu sensu, quando os meios se imbricam uns nos outros e se influenciam mutuamente, a ponto de, muitas vezes tornar-se impossível classificar um trabalho em categorias como cinema, vídeo, televisão, computação gráfica ou seja lá o que for."

Flavia Cesarino Costa (1995), analisando a revisão historiográfica da década de 70, mostra como alguns autores do período, (entre eles Tom Gunning e André Gauderault) trabalharam para superar a concepção evolucionista. Para a história do cinema que prevalecia até então, os primeiros filmes da virada do século XIX para o século XX eram importantes, porém meras tentativas desajeitadas de encontrar uma linguagem. Com a consolidação da gramática cinematográfica em «Grifith» e outros, este objetivo teria sido conquistado. As diferentes estruturas em relação à narratividade, naturalismo e outros pontos não eram consideradas e pensadas em si, mas em relação à cinematografia precedente.

Associando, como Arlindo Machado (que foi seu orientador), a construção da linguagem cinematográfica com diversos elementos da cultura, ela contraria a visão de "geração espontânea". Com isto, afirma que "(...) ao tratar com filmes nunca estamos lidando com objetos estáticos, mas com formas de comunicação que sofrem influências sociais e transformações contínuas".

E é neste sentido que a autora relaciona os diferentes períodos da história do audiovisual:

O mesmo hibridismo, muito evidente nos primeiros filmes, tem voltado a evidenciar-se de forma mais forte nas últimas décadas. A imagem da televisão e do vídeo, a aparição e generalização das imagens 
digitais e a intertextualização da imagem têm imposto mudanças radicais ao cinema, que por sua vez, tem respondido às vezes com banalização dessas influências e às vezes com a reinvenção criativa do próprio conceito de cinema (COSTA, 1995: 57).

A partir destas várias discussões que foram expostas, podemos pensar primeiramente neste caráter múltiplo destas muitas linguagens da imagem e as conseqüências para a construção da subjetividade contemporânea. Mas, além disso, é importante entender a essencial relação do corpo como sujeito neste processo, pensando que as relações entre sujeito e o aparelho, de formas das mais variadas na história, engendraram o que entendemos hoje como audiovisual.

Nos filmes que trabalho, percebi a necessidade de transcender tanto a discussão técnica sobre a evolução do maquinário, como o idealismo e romantismo da visão criativa e mental da arte. Imaginar um corpo que age e transforma, que se constrói e se desenvolve junto com a máquina, além de pensar um cinema como tecnologia dinâmica e ampla são propostas que parecem ser interessantes.

Relacionar estes tempos e técnicas tão distintas foi uma importante forma de iniciar as minhas questões. Pensar que esta questão da auto-imagem do sujeito-corpo através da mediação do aparelho possui uma história longa e complexa é essencial para entender esta complexidade midiática que registra o indivíduo a cada instante nos nossos dias.

\section{Bibliografia:}

ARANHA, Maria Lúcia \& MARTINS, Maria Helena. Filosofando: introdução à história da filosofia. São Paulo: Moderna, 1995.

BENJAMIN, Walter. "A obra de arte na era de sua reprodutibilidade técnica”. In: Walter Benjamin. Obras escolhidas: magia e técnica, arte e política. São Paulo: Brasiliense, 1993.

BERNARDET, Jean-Claude. O autor no cinema. São Paulo: Brasiliense/ Edusp, 1994.

CHARNEY, Leo \& SCHWARTZ, Vanessa. O cinema e a invenção da vida moderna. São Paulo: Cosac Naify, 2007.

COSTA, Flávia Cesarino. O primeiro cinema. São Paulo: Scritta, 1995.

DA VINCI, Leonardo. Anotações de Da Vinci por ele mesmo. São Paulo: Madras, 2004.

DUBOIS, Philippe. Cinema, vídeo, Godard. São Paulo: Cosac Naify, 2004.

HELLER, Agnes. O homem do renascimento. Lisboa: Editorial Presença, 1982.

MACHADO, Arlindo. Pré-cinemas e pós-cinemas. Campinas: Papirus, 2007.

MEDEIROS, Silvio. “Melancolia, de Dürer”. Disponível em: 
www.recantodasletras.uol.com.br/ensaios/441119. Acessado em: 03/05/2008.

PANOFSKY, Erwin. Idea: a evolução do conceito de belo. São Paulo: Martins Fontes, 1994.

SILVA, Ana Rita. "O sistema da perspectiva em Dürer”. Disponível em:

www.educ.fc.ul.pt/docentes/opombo/seminario/durer/matnapint.htm. Acessado em: 04/05/2008.

\section{Filmografia}

Lonely Girl. Disponível em: www.youtube.com/watch?v=dZN-Wye4rDE. Acessado em: 10/02/2007.

EDSON, Thomas. Sepentine Dance (filme reproduzido em vídeo). Disponível em:

www.youtube.com/results?q=serpentine+dance\&search_type. Black Maria Studio, EUA, 1894.

Sandow (filme reproduzido em vídeo). Disponível em:

http://www.youtube.com/watch?v=agvQxm_nPIw. Black Maria Studio, EUA, 1894.

\section{Notas:}

Trabalho apresentado no NP de Comunicação Audiovisual do VIII Nupecom - Encontro dos Núcleos de Pesquisa em Comunicação, evento componente do XXXI Congresso Brasileiro de Ciências da Comunicação (02-06/09/08).

\section{Mini Currículo :}

Mestrando em Multimeios da Unicamp. E-mail: gbarceloss@hotmail.com 